\title{
The burden of caring for adults with depression and suicidal ideation in five large European countries: analysis from the 2020 National Health and Wellness Survey
}

\author{
D. H. Jaffe ${ }^{1 *}$, B. L. Balkaran², L. Yue ${ }^{2}$, S. Mulhern-Haughey ${ }^{3}$ and J. Anjo ${ }^{4}$
}

\begin{abstract}
Background: Suicidal ideation (SI) affects approximately $30-40 \%$ of those with major depressive disorder (MDD). To date, studies have examined the substantial humanistic and economic burden to caregivers of persons with MDD, however little is known of the impact of caring for persons with MDD when $\mathrm{SI}$ is present. This study examined the additional burden imposed on caregivers for persons with unipolar depression and SI in five major European countries.
\end{abstract}

Methods: A retrospective, cross-sectional analysis was conducted in five European countries using 2020 Europe National Health Wellness Survey (France, Germany, Italy, Spain and the United Kingdom) to compare differences in health and economic outcomes between caregivers of adults with unipolar depression and SI (CAUD-SI) and caregivers of adults with unipolar depression without SI (CAUD-nSI). The outcomes assessed included health-related quality of life (HRQoL; Medical Outcomes Study Short Form [SF-12V2]), health status (Short-Form 6 Dimension [SF6D], EuroQol 5-Dimension 5-Level [EQ-5D-5L]), Work productivity and activity impairment (WPAl) and healthcare resource utilization (HRU). Linear mixed models and generalized linear mixed models adjusted for covariates were used to compare the two groups on outcomes of interest.

Results: Of 62,319 respondents, $0.89 \%(n=554)$ were CAUD-SI and $1.34 \%(n=837)$ were CAUD-nSI. In adjusted models, CAUD-SI reported greater humanistic burden than CAUD-nSI, with lower HRQoL (PCS: 42.7 vs. 45.0, $p<$ 0.001 and MCS: 37.5 vs. $38.9, p=0.007$ ) and health status (SF-6D: 0.57 vs $0.60, p<0.001$ and EQ-5D-5L: 0.58 vs 0.66 , $p<001)$. CAUD-SI respondents reported significantly higher economic burden than CAUD-nSI respondents for WPAI (percent activity impairment: $64.9 \%$ vs. $52.5 \%, p=0.026$ ) and HRU (provider visits: 10.0 vs. $7.9, p<0.001$, emergency room visits: 1.49 vs. $0.73, p<0.001$ and hospitalizations: 1.03 vs. $0.52, p<0.001$ ).

Conclusion: In five European countries, caregivers of adults with depression and SI experience additional humanistic and economic burden than caregivers of adults with depression and no Sl. Distinguishing caregiver groupings and their unique burden provide important insights for providing targeted support and interventions for both the patient and caregiver.

Keywords: Caregiver burden, Depression, Health-related quality of life, Healthcare resource utilization, Suicidal ideation, Work productivity and activity impairment

\footnotetext{
*Correspondence: dena.jaffe@cernerenviza.com

${ }^{1}$ Cerner Enviza, Tel Aviv, Israel

Full list of author information is available at the end of the article
}

\section{$\triangle B M C$}

(c) The Author(s). 2021 Open Access This article is licensed under a Creative Commons Attribution 4.0 International License, which permits use, sharing, adaptation, distribution and reproduction in any medium or format, as long as you give appropriate credit to the original author(s) and the source, provide a link to the Creative Commons licence, and indicate if changes were made. The images or other third party material in this article are included in the article's Creative Commons licence, unless indicated otherwise in a credit line to the material. If material is not included in the article's Creative Commons licence and your intended use is not permitted by statutory regulation or exceeds the permitted use, you will need to obtain permission directly from the copyright holder. To view a copy of this licence, visit http://creativecommons.org/licenses/by/4.0/ The Creative Commons Public Domain Dedication waiver (http://creativecommons.org/publicdomain/zero/1.0/) applies to the data made available in this article, unless otherwise stated in a credit line to the data. 


\section{Background}

Depression is a debilitating mental health condition that affects approximately 350 million people worldwide [1, 2 ]. Globally, $5.5 \%$ of all years lived with disability are attributed to depression [3]. In Europe, the lifetime prevalence of major depressive disorder (MDD) is estimated to be $11.3 \%$ [4]. It is the primary risk factor associated with suicide and suicidal ideation (SI) $[5,6]$ affecting $30-40 \%$ of those with MDD [7].

MDD and SI independently impose substantial humanistic burden defined and measured as the impact of the condition on health-related quality of life (HRQoL) and health status, and economic burden assessed using work productivity and medical and healthcare costs [814]. Moreover, the additional burden on persons with depression and SI was demonstrated in a recent crosssectional survey of five European countries [13]. The consequences of these burdens and impairments include an increased dependency and reliance on long-term assistance for daily activities [15]. This resultant spillover effect [16] on informal caregivers can result in physical, emotional, social, and financial strain $[17,18]$.

The prevalence of informal caregivers in Europe is reported to be $34.3 \%$ while intensive caregiving, defined as providing care for a minimum of $11 \mathrm{~h} /$ week, is estimated at $7.6 \%$; however, there is considerable variation in the prevalence of caregivers between countries [19-21]. In general, caregivers, regardless of their time investment, experience higher physical and psychological complications than non-caregivers [21]. Among caregivers, the humanistic and economic burden varies and is dependent on factors including the patient's disease [21-24] and its severity [25]. For example, caregivers of patients with psychiatric disorders experience higher rates of anxiety and depression compared to caregivers of patients with physical illness [21, 24]. Caregivers of adults with depression have approximately three times more frequent emergency room visits or hospitalizations compared to non-caregivers and $20 \%$ more healthcare resource utilization (HRU) than caregivers of adults with other chronic diseases [26]. An inverse relationship has been observed between disease severity and caregiver burden leading to reduced work participation, greater HRU use, and higher informal caregiving costs [25].

Clearly, a one-size-fits-all caregiver profile and burden is too simplistic for research, policy, and care implications [27, 28]. To date, studies related to depression caregiving have primarily focused on MDD and its impact on caregiver outcomes in relation to MDD severity; these studies did not account for the additional caregiver burden associated with SI. Further, high rates of SI among patients with depression in Europe necessitates a comprehensive understanding of the compounded burden of depression and SI on caregivers. The aim of this study was to assess the additional humanistic and economic burden experienced by persons caring for patients with depression and SI in five major European countries.

\section{Methods \\ Study population \\ Data source}

Data for this large, nationally representative, retrospective observational study were extracted from Kantar Health's 2020 Europe National Health and Wellness Survey (NHWS). The 2020 Europe NHWS is a self-administered, web-based survey of adults aged $\geq 18$ years $(N=62,319)$ in five European countries France, Germany, Italy, Spain, and the United Kingdom (UK). Respondents are identified through opt-in online survey panels using quota sampling by sex and age to create a demographically representative sample of the adult population in each country. To further ensure accurate representation of the survey, respondents may be recruited via telephone recruitment or invited to complete an online survey at private computer centers. The 2020 Europe NHWS received exemption from the Pearl Independent Review Board (IRB) in accordance with FDA 21 CFR 56.104 and DHHS 45 CFR 46.104 regulations (19-KANT-204). All survey data collected were anonymous.

\section{Study sample}

Respondents included in the current study were aged $\geq 18$ years, could read and write in the primary language of the country in which the study was conducted, and provided informed consent. Using the overall 2020 Europe NHWS sample of 62,319 respondents, we identified caregivers of adults with unipolar depression based on affirmative response to the survey query "Are you currently caring for an adult relative with any of the following conditions = depression?" Excluded were those who reported caring for an adult relative with bipolar disease or schizophrenia, since these patients have different underlying psychopathological factors even though their patterns of depressive episodes may be similar to adults with unipolar depression [29, 30]. The final sample cohort was grouped according to their response to "Has the person you care for with depression had thoughts that they would be better off dead or of hurting themselves in some way or have planned or attempted to end their life/commit suicide in the past six months?" into two categories: caregivers of persons with unipolar depression and SI (positive response) and caregivers of adults with unipolar depression but no SI (negative response) (see Table 1). 
Table 1 Sociodemographic and health characteristics of caregivers of unipolar depression + SI and caregivers of unipolar depression + no SI

\begin{tabular}{|c|c|c|c|}
\hline Characteristics & $\begin{array}{l}\text { Caregivers of unipolar depression }+\mathrm{SI} \\
(N=554)\end{array}$ & $\begin{array}{l}\text { Caregivers of unipolar depression }+ \text { no SI } \\
(N=837)\end{array}$ & $p$ value $^{a}$ \\
\hline \multicolumn{4}{|l|}{ Socio-demographic characteristics } \\
\hline Age (years), mean $\pm S D$ & $40.7 \pm 15.2$ & $43.5 \pm 15.2$ & $<0.001$ \\
\hline \multicolumn{4}{|l|}{ Gender, n (\%) } \\
\hline Female & $298(53.8)$ & $487(58.2)$ & \multirow[t]{2}{*}{0.106} \\
\hline Male & $256(46.2)$ & $350(41.8)$ & \\
\hline \multicolumn{4}{|l|}{ Marital Status, n (\%) } \\
\hline Married or living with partner & $362(65.5)$ & $540(64.9)$ & \multirow[t]{2}{*}{0.831} \\
\hline Not Married & $191(34.5)$ & $292(35.1)$ & \\
\hline \multicolumn{4}{|l|}{ Education, n (\%) } \\
\hline University degree & $207(37.8)$ & $270(32.5)$ & \multirow[t]{2}{*}{0.040} \\
\hline Less than university degree & $340(62.2)$ & $562(67.5)$ & \\
\hline \multicolumn{4}{|l|}{ Annual Household Income, n (\%) } \\
\hline Less than $€ 49,999$ or $£ 39,999$ & 409 (76.9) & $599(76.6)$ & \multirow[t]{2}{*}{0.906} \\
\hline$€ 50,000$ or $£ 40,000$ or more & $123(23.1)$ & $183(23.4)$ & \\
\hline \multicolumn{4}{|l|}{ Employment Status, n (\%) } \\
\hline Employed & $382(69.0)$ & $513(61.3)$ & \multirow[t]{3}{*}{0.014} \\
\hline Not employed & $113(20.4)$ & $211(25.2)$ & \\
\hline Retired & $59(10.6)$ & $113(13.5)$ & \\
\hline \multicolumn{4}{|l|}{ Health characteristics } \\
\hline \multicolumn{3}{|l|}{ Body Mass Index, n (\%) } & \multirow[t]{6}{*}{0.137} \\
\hline Underweight $\left(<18.5 \mathrm{~kg} / \mathrm{m}^{2}\right)$ & $33(6.0)$ & $30(3.6)$ & \\
\hline Normal weight $\left(18.5\right.$ to < $25.0 \mathrm{~kg} / \mathrm{m}^{2}$ ) & $217(39.2)$ & $330(39.4)$ & \\
\hline Overweight ( 25.0 to $<30.0 \mathrm{~kg} / \mathrm{m}^{2}$ ) & $154(27.8)$ & $266(31.8)$ & \\
\hline Obese ( $30.0 \mathrm{~kg} / \mathrm{m}^{2}$ and above) & $109(19.7)$ & $161(19.2)$ & \\
\hline Decline to answer & $41(7.4)$ & $50(6.0)$ & \\
\hline BMI, mean \pm SD (valid n) & $\begin{array}{l}26.3 \pm 7.0 \\
(n=513)\end{array}$ & $\begin{array}{l}26.4 \pm 6.3 \\
(n=787)\end{array}$ & 0.684 \\
\hline \multicolumn{3}{|l|}{ Smoking Status, n (\%) } & \multirow[t]{4}{*}{$<0.001$} \\
\hline Current & $244(44.0)$ & $276(33.0)$ & \\
\hline Former & $118(21.3)$ & $194(23.2)$ & \\
\hline Never & $192(34.7)$ & $367(43.8)$ & \\
\hline \multicolumn{2}{|l|}{ Alcohol use, n (\%) } & & \multirow[t]{3}{*}{0.188} \\
\hline Currently consume & $439(79.2)$ & $638(76.2)$ & \\
\hline Currently do not consume & $115(20.8)$ & $199(23.8)$ & \\
\hline Exercise, $^{\mathrm{b}} \mathrm{n}(\%)$ & $421(76)$ & $571(68.2)$ & 0.002 \\
\hline \multicolumn{3}{|l|}{ CCl Categories, n (\%) } & \multirow[t]{4}{*}{0.161} \\
\hline 0 & $368(66.4)$ & $594(71.0)$ & \\
\hline 1 & $106(19.1)$ & $146(17.4)$ & \\
\hline $2+$ & $80(14.4)$ & $97(11.6)$ & \\
\hline $\mathrm{CCl}$, mean $\pm \mathrm{SD}$ & $0.71 \pm 1.47$ & $0.53 \pm 1.16$ & 0.012 \\
\hline \multicolumn{3}{|c|}{ Self-reported medical diagnosis of anxiety, $n(\%)$} & \multirow[t]{3}{*}{0.141} \\
\hline Yes experienced + No diagnosis & $84(15.2)$ & $137(16.4)$ & \\
\hline Yes experienced + Yes diagnosis & $188(33.9)$ & $249(29.7)$ & \\
\hline
\end{tabular}


Table 1 Sociodemographic and health characteristics of caregivers of unipolar depression + SI and caregivers of unipolar depression + no SI (Continued)

\begin{tabular}{|c|c|c|c|}
\hline Characteristics & $\begin{array}{l}\text { Caregivers of unipolar depression }+\mathrm{SI} \\
(N=554)\end{array}$ & $\begin{array}{l}\text { Caregivers of unipolar depression }+ \text { no } \mathrm{SI} \\
(N=837)\end{array}$ & $p$ value $^{\mathrm{a}}$ \\
\hline Did not experience & $282(50.9)$ & $451(53.9)$ & \\
\hline \multicolumn{3}{|c|}{ Self-reported medical diagnosis of depression, $\mathbf{n}(\%)$} & $<0.001$ \\
\hline Yes experienced + No diagnosis & $125(22.6)$ & $155(18.5)$ & \\
\hline Yes experienced + Yes diagnosis & $265(47.8)$ & $314(37.5)$ & \\
\hline Did not experience & $164(29.6)$ & $368(44.0)$ & \\
\hline \multicolumn{3}{|c|}{ Self-reported medical diagnosis of sleep problems, $n(\%)$} & 0.018 \\
\hline Yes experienced + No diagnosis & $148(26.7)$ & $205(24.5)$ & \\
\hline Yes experienced + Yes diagnosis & $82(14.8)$ & $91(10.9)$ & \\
\hline Did not experience & $324(58.5)$ & $541(64.6)$ & \\
\hline \multicolumn{2}{|l|}{ PHQ- 9 score, n (\%) } & & $<0.001$ \\
\hline Minimal, $0-4$ & $85(15.3)$ & $213(25.4)$ & \\
\hline Mild, 5-9 & $112(20.2)$ & $282(33.7)$ & \\
\hline Moderate, 10-14 & $156(28.2)$ & $180(21.5)$ & \\
\hline Moderately severe, 15-19 & $116(20.9)$ & $106(12.7)$ & \\
\hline Severe, 20-27 & $85(15.3)$ & $56(6.7)$ & \\
\hline PHQ- 9 score, mean \pm SD & $12.3 \pm 6.8$ & $9.1 \pm 6.3$ & $<0.001$ \\
\hline
\end{tabular}

Note: $\mathrm{CCl}$ Charlson comorbidity index, PHQ-9 Patient Health Questionnaire (9 questions), SI Suicidal ideation

${ }^{a}$ Statistical testing for categorical variables were calculated using Chi-square test and for continuous variables using ANOVA, with statistically significant values in bold

${ }^{\mathrm{b}}$ Exercise was defined as yes/no reporting exercising for $20 \mathrm{~min}$ or more at least on one occasion in the past 30 days

\section{Measures}

\section{Sociodemographic and health characteristics}

Demographic measures included age, gender (male or female), marital status (married/living with partner or not married), education (university degree or less than university degree), household income (more than $€ 50,000 / £ 40,000$ or less than $€ 49,999 / £ 39,999)$ and employment status (employed, not employed or retired).

Health characteristics examined were body mass index (BMI) (underweight $\left[<18.5 \mathrm{~kg} / \mathrm{m}^{2}\right]$, normal weight $[18.5$ to $\left.<25.0 \mathrm{~kg} / \mathrm{m}^{2}\right]$, overweight $\left[25.0\right.$ to $\left.<30.0 \mathrm{~kg} / \mathrm{m}^{2}\right]$, obese $\left[\geq 30.0 \mathrm{~kg} / \mathrm{m}^{2}\right]$, exercise at least $20 \mathrm{~min}$ on at least one occasion in the past 30 days (no or yes), alcohol consumption (consume or does not consume) and smoking status (current, former, or never). Burden of non-psychiatric comorbidities was estimated using the Charlson Comorbidity Index (CCI) [31]. The CCI index is a function of health condition and summation of overall result obtained in the survey questionnaire that assess disease experience ("Which of the following conditions have you ever experienced?"). Higher total index score implies greater comorbidities. Mental health related conditions, anxiety, depression, and sleep difficulties were categorized according as those experiencing the condition with or without a diagnosis. In addition, the depression screening Patient Health Questionnaire (PHQ-9) score was used to characterize respondents depressive symptoms as minimal (0-4), mild (5-9), moderate (10$14)$, moderately severe (15-19), and severe (20-27).

\section{Humanistic and economic outcomes}

HRQoL was determined using the Medical Outcomes Study 12-Item Short-Form Health Survey version 2 (SF12v2) [32, 33], a multipurpose, generic health status instrument. Respondents are asked 12 questions based on the past four weeks. These questions are designed to map eight different health domains:

- Physical functioning - limitations in moderate physical activity

- Physical role functioning - accomplishes less due to physical health

- Bodily pain - pain interferences with work (in and out of home)

- General health - general health rating

- Social role functioning - interference of physical health or emotional problems with social activities

- Emotional role functioning - accomplishes less due to emotional problems

- Vitality - energy and fatigue

- Mental health - psychological distress and wellbeing 
Two component summary scores assessed were physical component summary (PCS) and mental component summary (MCS) scores. Health domain scores are normally distributed over a range of 0 to 100 , mean average of summary score equals 50 with a standard deviation (SD) of 10 for the US general population. Scores can be interpreted based on standard US derived scoring algorithm or country specific scoring or comparison groups of interest. Higher scores for each domain and summary score reflect better quality of life. A minimal clinically important difference (MCID) for the MCS and PCS is considered 3.0 [34].

Short-Form 6 Dimension (SF-6D) derived from SF12v2 (prior 4 weeks) [35] and the EuroQol 5-Dimension 5-Level version (EQ-5D-5L) (current health status, i.e., 'today') [36, 37]) were used to assess health status. In general, health status measures are normally distributed and range between 0 (health state equivalent to death) to 1 (health state equivalent to perfect health). Scoring of the SF-6D considers 6 of the 8 SF-12 domains, including physical functioning, physical role functioning, emotional functioning, social functioning, bodily pain, mental health and vitality. The EQ-5D-5L consists of 5 dimensions: mobility, self-care, usual activities, pain/discomfort, and anxiety/depression often used to evaluate quality-adjusted life years associated with a health state [38]. An MCID of 0.07 is considered for the EQ-5D-5L and 0.04 for the SF-6D [39].

Work productivity loss and activity impairment due to ill health for employed (full-time, part-time or selfemployed) respondents was assessed using the Work Productivity and Activity Impairment questionnaire (WPAI) [40]. It is a six-item validated instrument that measures the aspects of work productivity based on four subscales: absenteeism (\% of work time missed due to health problems in the past seven days), presenteeism (\% impairment at work due to health problems in the past seven days), overall work productivity loss metric (overall $\%$ estimate combining absenteeism and presenteeism in the past seven days), and activity impairment (\% impairment in non-work activities due to one's health in the past seven days). Higher percentage value for each of the subscale correspond to greater impairment.

HRU data were defined as frequency of visits to various health care providers (HCPs) in the past six months. These include traditional providers (e.g., general practitioners, nurses) and specialist visits (psychiatrist or psychologist/therapist), emergency room (ER) visits, as well as hospitalizations.

\section{Statistical analysis}

The study compared the characteristics and outcomes of caregivers of unipolar depression + SI (CAUD-SI) and caregivers of unipolar depression + no SI (CAUD-nSI).
Descriptive statistics included means and SDs for continuous variables and frequencies and percentages for categorical variables. Missing data is minimized by allowing respondents the option of 'decline to answer' or 'prefer not to answer' for items asking about potentially sensitive topics, such as weight or income. The resultant small amount of missing data are expected to be missing at random (MAR).

Bivariate analyses evaluated differences between caregiver groups using ANOVA for continuous variable and chi-square tests for categorical variables. Multivariate analyses were employed to examine the association between caregiver group and outcome after adjusting for potential confounding factors. Model choices were determined according to the distribution of each outcome. Linear mixed models with gaussian distribution were used for health outcomes (EQ-5D-5L, SF-6D, and SF$12 \mathrm{v} 2$ scores) and generalized linear mixed models with negative binomial distribution were used for economic outcomes (WPAI metrics, healthcare resource utilization) after controlling for the confounding effect of sociodemographic (age, education, employment status) and health status (smoking status, exercise, CCI) factors using backward models. Adjusted means, standard errors (SE), regression coefficients, $p$-values, and 95\% confidence intervals were calculated for all the dependent variables. $P<0.05$ was considered as statistically significant.

All statistical analyses were conducted using SPSS v23.0, SAS v9.4, and/or R v3.6.0 or higher.

\section{Results \\ Caregiver characteristics}

A total of 62,319 respondents (France $N=15,152$; Germany $N=15,020$; Italy $N=10,026$; Spain $N=7074$; UK $N=15,047$ ) were included in the study. Of these respondents, $554(0.89 \%)$ were identified as CAUD-SI whereas 837 respondents (1.34\%) were identified as CAUD-nSI (Fig. 1).

Unadjusted comparisons showed that all caregivers, regardless of subgroup, were more often women (CAUD$\mathrm{SI}=53.8 \%$ vs. CAUD-nSI $=58.2 \%, p=0.106$ ), married (CAUD-SI $=65.5 \%$ vs. CAUD-nSI $=64.9 \%, p=0.831$ ), and reported lower annual household income (CAUD$\mathrm{SI}=76.9 \%$ vs. CAUD-nSI $=76.6 \%, p=0.906) \quad($ Table 1$)$. Differences between groups were observed with CAUDSI respondents being younger $(40.7 \pm 15.2$ years vs. $43.5 \pm 15.2$ years, $p<0.001$ ), more educated (university degree: $37.8 \%$ vs. $32.5 \%, p=0.040)$ and more likely to be employed $(69.0 \%$ vs. $61.3 \%, p=0.014)$ compared to CAUD-nSI respondents, respectively. CAUD-SI respondents were more likely to smoke $(44.0 \%$ vs. $33.0 \%$, overall $p<0.001)$ and exercise $(76.0 \%$ vs. $68.2 \%, p=0.002)$ 


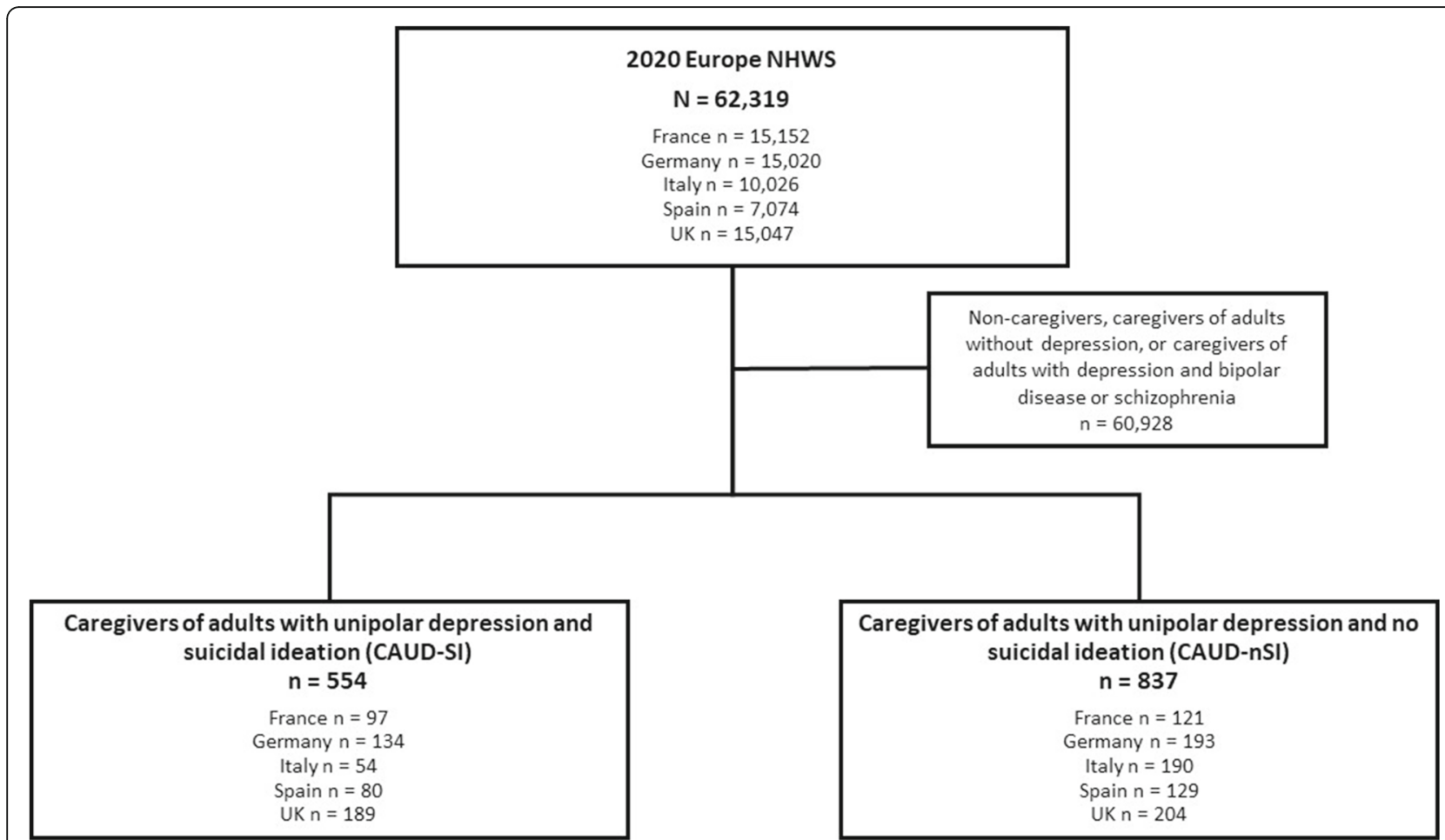

CAUD-SI, Caregivers of adults with unipolar depression and suicidal ideation; CAUD-nSI, Caregivers of adults with unipolar depression and no suicidal ideation; NHWS, National Health and Wellness Survey

Fig. 1 Study population from five European countries: 2020 NHWS

and had a higher average CCI score $(0.71$ vs. $0.53, p=$ 0.012).

CAUD-SI respondents reported higher mental health burden in terms of self-reported medical diagnosis (SRMD) of depression ( $47.8 \%$ vs. $37.5 \%$, overall distribution $p<0.001)$ and sleep problems $(14.8 \%$ vs. $10.9 \%$, overall distribution $p<0.05$ ) (Table 1). Additionally, differences in PHQ-9 scores were noted to be significant between CAUD-SI and CAUD-nSI $(p<0.001)$, with higher proportion of CAUD-SI respondents reporting moderate, moderately severe, and severe depression.

\section{Unadjusted comparison of outcome for CAUD-SI and CAUD-nSI}

Unadjusted analyses of outcomes related to caregiving for depression with and without SI indicated substantially higher burden among CAUD-SI respondents compared with CAUD-nSI (Table S1).

CAUD-SI respondents reported significantly lower scores for each domain - physical functioning (44.9 vs. $48.7, p<0.001)$, bodily pain ( 41.8 vs. $44.3, p<0.001)$, physical role functioning ( 40.4 vs. $43.7, p<0.001$ ), emotional role functioning ( 34.2 vs $38.7, p<0.001)$, and social role functioning (38.1 vs. $41.5, p<0.001$ ), as well as lower PCS (46.2 vs. 48.5, $p<0.001)$ and MCS scores (38.4 vs. $40.3, p<0.001)$.
CAUD-SI respondents also reported lower health status as measured by EQ-5D-5L (0.63 vs. $0.73, p<0.001)$ and SF-6D health utilities (0.60 vs. $0.64, p<0.001)$ than CAUD-nSI.

In terms of WPAI, CAUD-SI respondents reported higher levels of absenteeism (24.1 vs. 14.6, $p<0.001$ ), presenteeism ( 48.4 vs. $34.7, p<0.001$ ), overall work productivity loss (54.7 vs. 39.6, $p<0.001)$, and activity impairment $(49.0$ vs. $39.5, p<0.001)$ compared with CAUD-nSI respondents.

When assessing HRU, a higher percentage of CAUDSI respondents reported visit to a psychologists or therapists in the past six months $(12.3 \%$ vs. $8.5 \%, p=0.021)$, however no difference was noted for visits to a psychiatrist $(11.2 \%$ vs. $8.6 \%, p=0.109)$ compared with CAUDnSI respondents. Further, significantly higher traditional provider visits ( 7.9 vs. $6.5, p=0.005)$, ER visits (1.48 vs. $0.59, p<0.001)$, and hospitalizations $(0.83$ vs. $0.32, p<$ 0.001) were observed in CAUD-nSI respondents than CAUD-nSI.

\section{Adjusted comparison of outcomes for CAUD-SI and CAUD-nSI}

Multivariable models adjusted after controlling for covariates showed that CAUD-SI versus CAUD-nSI had substantially lower adjusted means for MCS (37.5 vs. 
38.9, $p=0.007)$ and PCS (42.7 vs. 45.0, $p<0.001)$ (Table S2, Fig. 2). Specific domains of the SF-12v2 with statistically significant marginal mean differences between groups included physical functioning (difference $=3.5$ ), bodily pain (difference $=2.4$ ), physical role functioning (difference $=3.0$ ), emotional role functioning (difference $=4.0$ ), and social role functioning (difference $=3.0$ ).

In the adjusted model, the CAUD-SI group had significantly poorer health status compared to CAUD-nSI for both the SF-6D $(0.57$ vs $0.60, p<0.001)$ and EQ-5D-5L (0.58 vs $0.66, p<001)$. The MCID of $>0.07$ points was observed for the EQ-5D-5L (Table S2, Fig. 3).

Comparison of WPAI in adjusted models showed no significant differences in absenteeism, presenteeism, or overall work impairment between CAUD-SI and CAUDnSI respondents $(p>0.05)$, but differences in activity impairment were observed between the two groups ( $p=$ 0.026). (Table S2, Fig. 4).

CAUD-SI respondents reported higher estimated marginal means for provider visits $(10.0$ vs. $7.9, p<0.001)$, ER visits (1.49 vs. $0.73, p<0.001)$, and hospitalizations (1.03 vs. $0.52, p<0.001)$ compared with CAUD-nSI respondents (Table S2, Fig. 5).

\section{Discussion}

The present study reports the additional burden experienced by caregivers of adults with unipolar depression due to presence of SI across five European countries. We show that when compared to those caring for adults with unipolar depression and no SI, caregivers of adults with unipolar depression and SI experience a substantial excess humanistic and economic burden, with lower health status and HRQoL, and increased HRU. This observation extends our previous work by showing the increased burden of caregiving for adults with depression compared to other diseases [26].

Factors associated with caregiver burden include both caregiver and patient characteristics [21-25, 27, 28, 4143]. For example, caregiver characteristics associated with poor outcomes include age, gender, socioeconomic status, levels of informal support, comorbidities, and choice of being a caregiver [21, 41, 43]. Patient characteristics affecting caregiver burden include, relationship to the carer, type, severity, and level of disability of disease $[27,28]$. A meta-analysis examining the effects of caregiving on physical health showed that the patient's overall impairment and cognitive complications in addition to the caregiver's involvement (number of caregiving hours per day/per week and caregiving tasks, overall duration of caregiving), physical health, and available social support impact the degree of caregiving burden $[41,43]$.

In this study, demographic characteristics of caregivers of adults with depression are consistent with previous report, with a little over half of the respondents being female [44] and two-thirds married or living with their partner and employed [45]. Interestingly, characteristics of caregivers for unipolar depression and SI differed

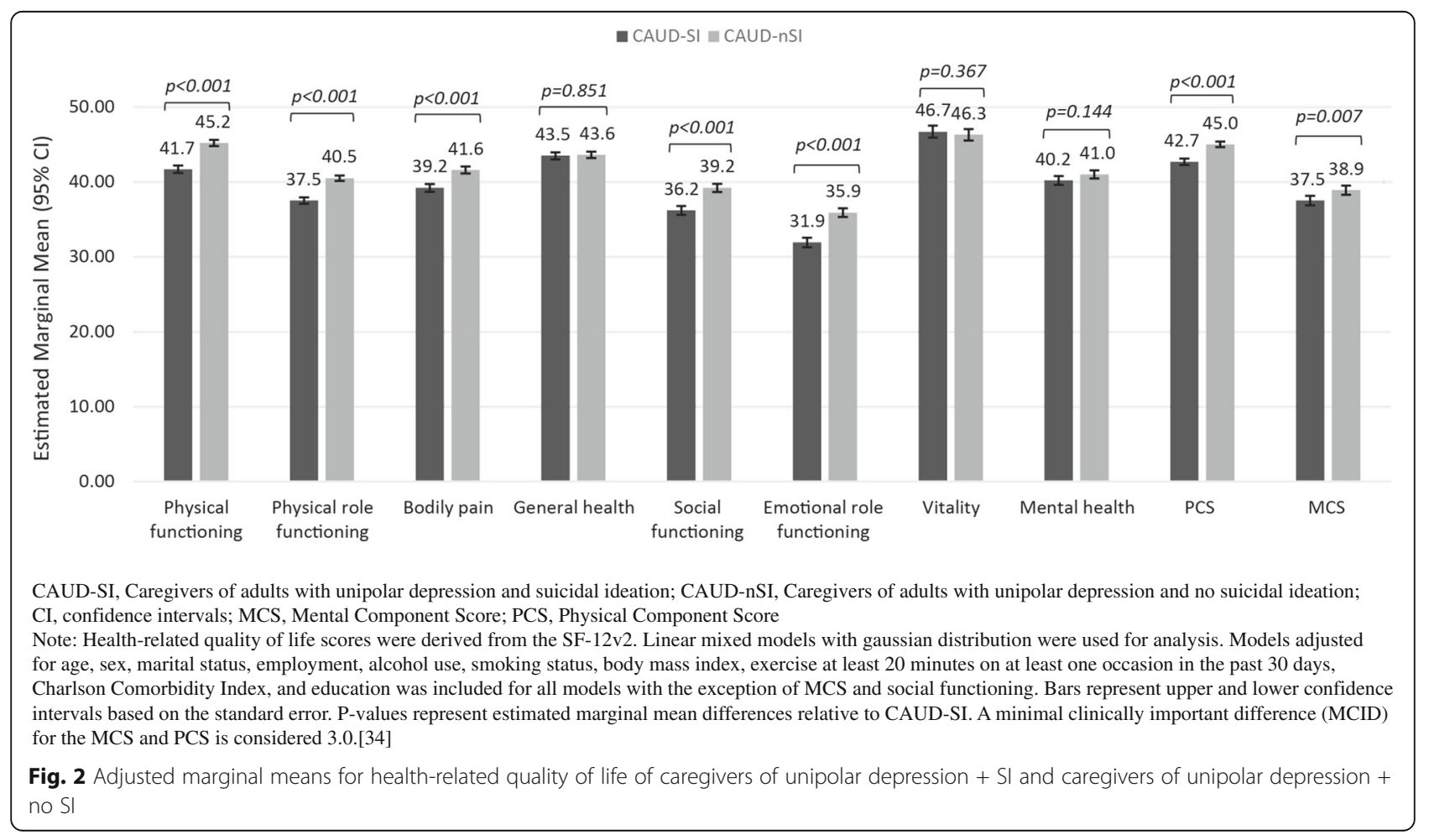




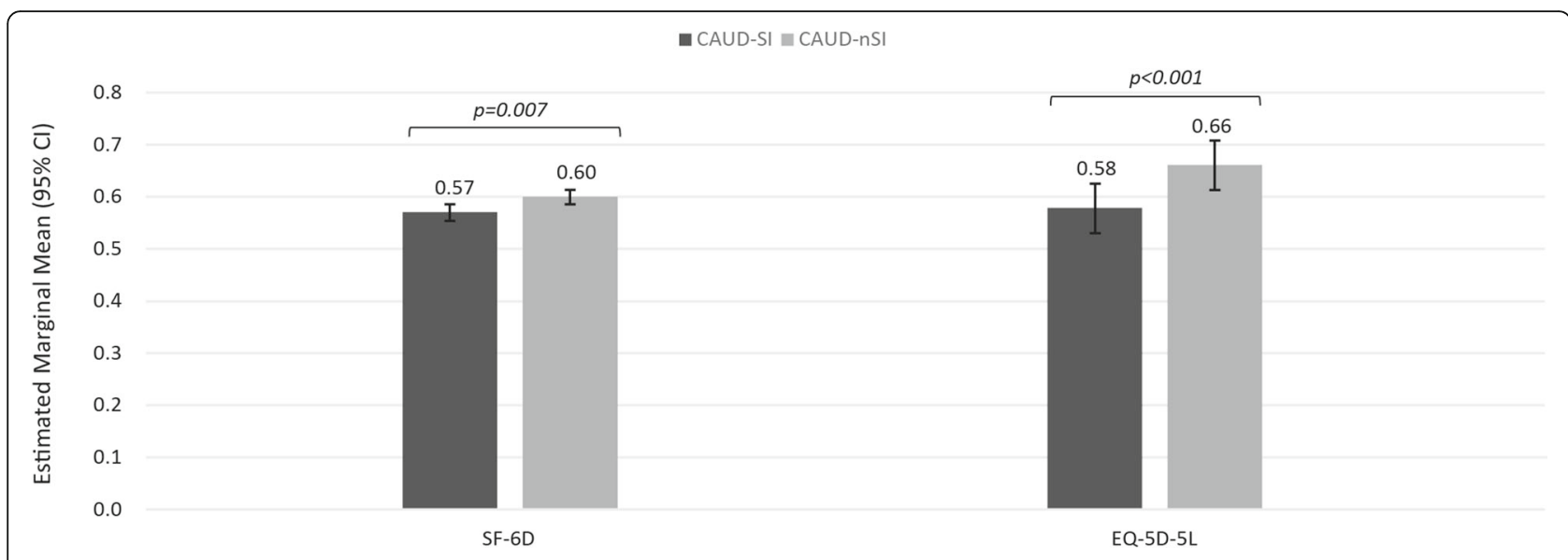

CAUD-SI, Caregivers of adults with unipolar depression and suicidal ideation; CAUD-nSI, Caregivers of adults with unipolar depression and no suicidal ideation; CI, confidence intervals; EQ-5D-5L, EuroQual 5 Dimension 5 Levels; SF-6D, Short-Form 6 Dimension.

Note: Health status for the SF-6D was derived from the SF-12v2. Linear mixed models with gaussian distribution were used for analysis. Models adjusted for age, sex, marital status, education, alcohol use, smoking status, body mass index, exercise at least 20 minutes on at least one occasion in past 30 days, and Charlson Comorbidity Index. Bars represent upper and lower confidence intervals based on the standard error. P-values represent estimated marginal mean differences relative to CAUD-SI. A minimal clinically important difference (MCID) of 0.07 is considered for the EQ-5D-5L and 0.04 for the SF-6D.[39]

Fig. 3 Adjusted marginal means for health status of caregivers comparing unipolar depression + SI and caregivers of unipolar depression + no SI

significantly from those without SI by age, employment, smoking status, CCI, and mental health (diagnosis and/ or experience) - anxiety, depression, and sleep issues. Differences in socio-demographic and health characteristics may be predictors (e.g., age, employment) or outcomes (e.g., anxiety, depression) associated with being a caregiver for patients with depression and SI. These findings reflect a critical distinction between caregiver groups with likely different needs $[27,28]$.

The impact of SI on the caregiver of patients with depression is most prominent in the functional domains and for the domain related to bodily pain of the SF$12 \mathrm{v} 2$, whereby an MCID was present for the physical, emotional role, and social functional scores. In contrast,

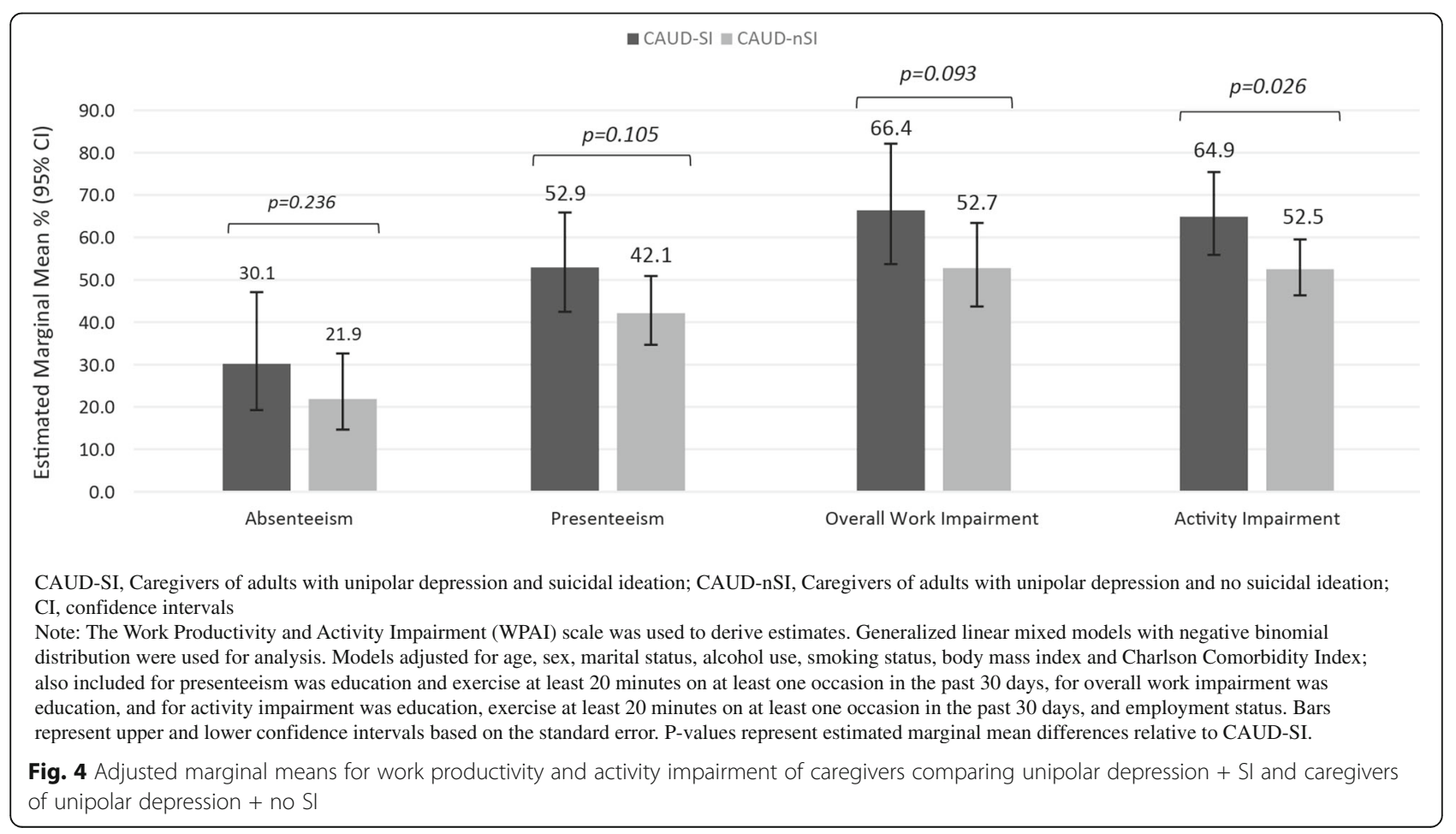




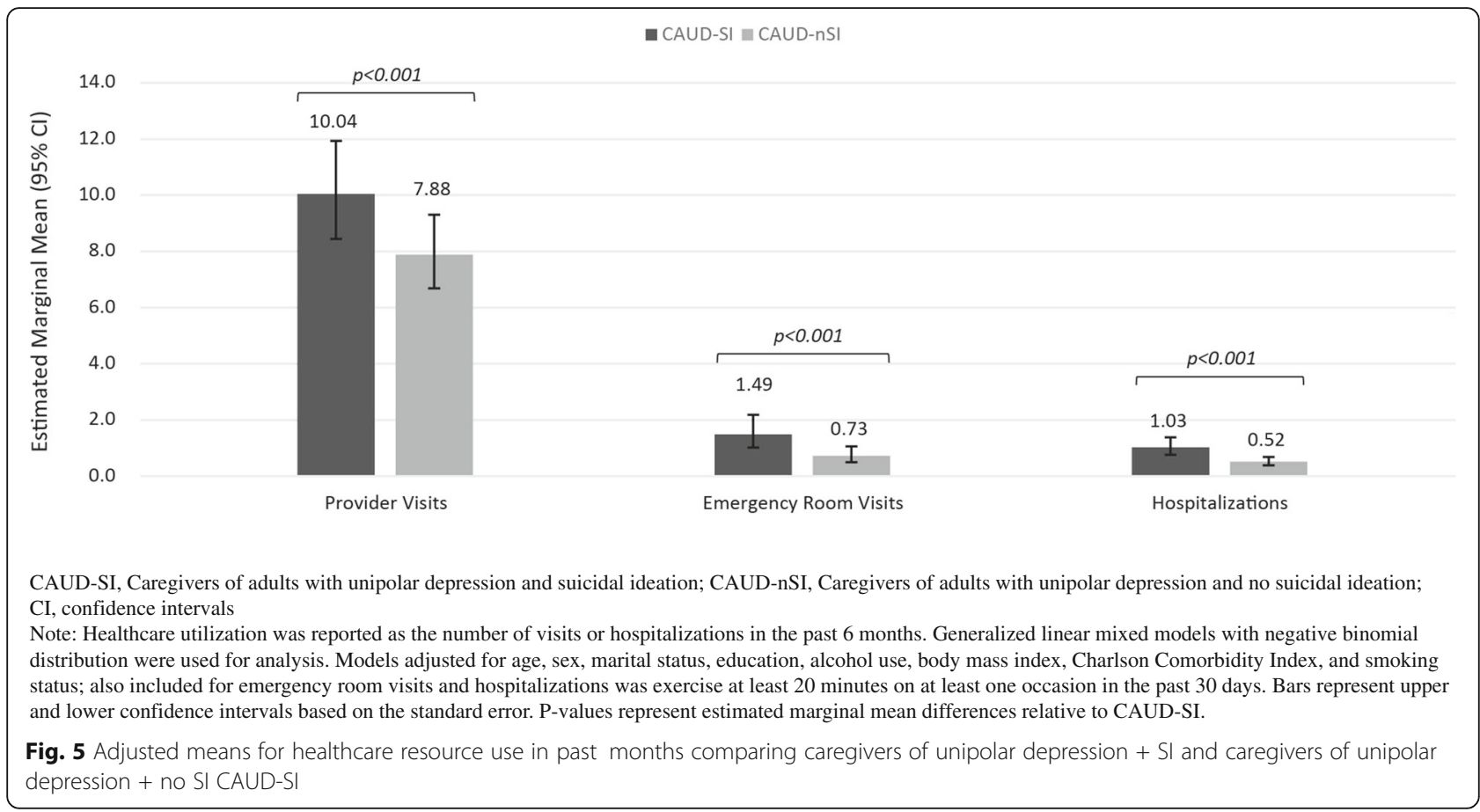

no statistically significant group differences were observed for general health, mental health, or vitality. Furthermore, caregivers of patients with unipolar depression and SI reported greater impairment of health status for both utility scores; however, an MCID was observed for the EQ-5D-5L and not the SF-6D. These findings suggest that the additional burden of caring for depression with SI is likely related to more practical limitations (EQ-5D) and less to a general sense of wellbeing (SF-6D) [46].

The negative impact of caregiving on work participation, perhaps another indicator of a functional domain, is a notable finding as it highlights the patient's burden outside of the family space and into the workplace and society [25]. Recent studies of caregivers of chronic illness and specifically depression reported greater work and overall activity impairment, with higher levels of absenteeism and presenteeism and related costs compared with non-caregivers $[25,26,47]$. In this study, the additional work-related burden among employed caregivers was not observed in fully adjusted models. However, overall activity impairment was substantially higher among those caring for depression and SI than depression alone, which are consistent with the functional limitations observed for HRQoL measures.

Higher HRU (provider visits, ER visits, hospitalization) were reported for those caring for adults with unipolar depression and SI compared to those without SI. In a similar cross-sectional study in Europe, of patients with unipolar depression with and without SI, higher HRU was observed in patients with unipolar depression and
SI compared to those with unipolar depression without SI [13]. As patients with more severe depression have higher overall rates of hospitalization and specifically SIrelated hospitalizations, it is likely that caregivers' heightened physical and psychological stresses lead to negative health outcomes requiring care.

\section{Strengths and limitations}

The strengths of the study include self-reported outcomes that are uniformly derived across all five European countries. The sample of caregivers is drawn from a representative sample of the general population of each country in which the study was conducted, which notably differs from many caregiver studies that use convenience samples [27, 43]. Recall bias is minimized since most survey questions are based on current practice and attitude. Also, missing data is minimized by including 'don't know' or 'decline to answer' as options for items regarding potentially sensitive topics, such as weight or income.

The present study is not without limitations. The NHWS is a panel-based survey and may not reach segments of populations including those with limited internet access, disabilities, or lack of familiarity with online surveys. Further, caregivers who can read and write in the language of their resident country were included in the NHWS, thereby excluding potential caregivers who do not meet this criteria; although we would assume this potential bias to be minimal as most caregivers of their adult relatives are likely fluent in their country of residence's language. The study relies on self-reported data 
and therefore diagnosis of depression and other relevant diagnoses (e.g., those used in the comorbidity index) and report of healthcare visits cannot be confirmed. Also, since only measured variables were accounted for in regression analysis, there is possibility of groups differing on unmeasured variables that may have an impact on outcomes. Finally, the NHWS does not capture caregiving for a patient based on patient characteristics such as severity, medication use, or duration of their disease. This in turn, is likely to affect the assessment of burden as caregiving is impacted by degree of severity of disease and depression is a complex disorder that is modulated by several factors including severity, duration and overall management of disease.

\section{Conclusions}

The present study shows that in these five European countries, caregivers of adults with depression and SI compared to caregivers of adults with depression without SI experience an additional humanistic and economic burden. It is important to critically assess each unique caregiver group and their associated burden in order to estimate burden as well as provide targeted support and interventions for both the patient and caregiver.

\section{Abbreviations \\ BMI: Body mass index; CAUD-nSI: Caregivers of unipolar depression + no Sl; CAUD-SI: Caregivers of unipolar depression + SI; CCl: Charlson Comorbidity Index; ER: Emergency room; EQ-5D-5L: EuroQol 5-Dimension 5-Level; HCP: Health care provider; HRU: Healthcare resource utilization; HRQOL: Health-related quality of life; IRB: Independent review board; MDD: Major depressive disorder; MCS: Mental component summary; MCID: Minimal clinically important difference; MAR: Missing at random; NHWS: National Health and Wellness Survey; PHQ: Patient health questionnaire; PCS: Physical component summary; SD: Standard deviation; SE: Standard error; SF-12V2: Short-Form Health Survey Version 2; SF-6D: Short- Form 6 Dimension; SI: Suicidal ideation; SR-MD: Self-reported medical diagnosis; UK: United Kingdom; WPAI: Work productivity and activity impairment questionnaire}

\section{Supplementary Information}

The online version contains supplementary material available at https://doi. org/10.1186/s12888-021-03511-9.

Additional file 1.

\section{Acknowledgements}

Medical writing support was provided by Kirtika Verma, PhD and Ramu Periyasamy, Ph.D., Indegene Pvt. Ltd., Bangalore, India.

\section{Authors' contributions}

All authors were involved in study design and methodology, DHJ, BLB, and $Y L$ were involved in data analysis, and DHJ, BLB, YL, SMH, and JA were involved in reporting. All authors approved the final manuscript.

\section{Funding}

Janssen-Cilag BV provided funding to Cerner Enviza for access to survey data and was involved in all aspects of the study, including research design, interpretation of data and drafting of the manuscript.

\section{Availability of data and materials}

NHWS data used in this study are available for noncommercial research and validation purposes, upon request. Interested individuals may access the data for the purposes above in the same manner as the authors did without any additional restrictions. Interested parties should contact the corresponding author on reasonable request.

\section{Declarations}

\section{Ethics approval and consent to participate}

The 2020 Europe NHWS received exemption from the Pearl Independent Review Board (IRB). All NHWS respondents provided (written) electronic informed consent prior to participating.

\section{Consent for publication}

Not applicable.

\section{Competing interests}

DHJ, BLB, and YL are employees of Cerner Enviza. SMH and JA are employees of Janssen-Cilag.

\section{Author details}

${ }^{1}$ Cerner Enviza, Tel Aviv, Israel. ${ }^{2}$ Cerner Enviza, New York, NY, USA. ${ }^{3}$ Janssen Pharmaceuticals, Dublin, Ireland. ${ }^{4}$ Janssen-Cilag Farmaceutica, Porto Salvo, Portugal.

Received: 1 June 2021 Accepted: 21 September 2021

Published online: 09 November 2021

\section{References}

1. World Federation for Mental Health (WFMH). Depression: A Global Crisis. Texas; 2020. https:/www.who.int/mental_health/management/depression/ wfmh_paper_depression_wmhd_2012.pdf.

2. World Health Organization: Depression Fact Sheet. https://www.who.int/ newsroom/fact-sheets/detail/depression. Accessed 5 Sept 2021.

3. Institute for Health Metrics and Evaluation (IHME). GBD 2019 Cause and risk summary: depression. Seattle: IHME, University of Washington; 2020. http:// www.healthdata.org/results/gbd_summaries/2019. Accessed 5 Sept 2021.

4. Gutiérrez-Rojas L, Porras-Segovia A, Dunne H, Andrade-González N, Cervilla JA. Prevalence and correlates of major depressive disorder: a systematic review. Braz J Psychiatry. 2020;42(6):657-72. https://doi.org/10.1590/151 6-4446-2020-0650.

5. Roca M, del Amo AR-L, Riera-Serra P, Pérez-Ara MA, Castro A, Roman Juan J, et al. Suicidal risk and executive functions in major depressive disorder: a study protocol. BMC Psychiatry. 2019;19(1):253. https://doi.org/10.1186/s12 888-019-2233-1.

6. Hawton K, Casañas i Comabella C, Haw C, Saunders K. Risk factors for suicide in individuals with depression: a systematic review. J Affect Disord. 2013;147(1-3):17-28. https://doi.org/10.1016/j.jad.2013.01.004.

7. Isometsä E. Suicidal behaviour in mood disorders - who, when, and why? Can J Psychiatry. 2014;59(3):120-30. https://doi.org/10.1177/0706743714 05900303.

8. IsHak WW, Mirocha J, James D, Tobia G, Vilhauer J, Fakhry H, et al. Quality of life in major depressive disorder before/after multiple steps of treatment and one-year follow-up. Acta Psychiatr Scand. 2015;131(1):51-60. https://doi. org/10.1111/acps.12301.

9. Evans-Lacko S, Knapp M. Global patterns of workplace productivity for people with depression: absenteeism and presenteeism costs across eight diverse countries. Soc Psychiatry Psychiatr Epidemiol. 2016;51(11):1525-37. https://doi.org/10.1007/s00127-016-1278-4.

10. Chow W, Doane MJ, Sheehan J, Alphs L, Le H. Economic burden among patients with major depressive disorder: an analysis of healthcare resource use, work productivity, and direct and indirect costs by depression severity. Am J Manag Care. 2019. https://ajmc.s3.amazonaws.com/_media/_pdf/A JMC_A896_02_2019_EconomicBurden.pdf. Accessed 5 Sept 2021.

11. Fairweather-Schmidt AK, Batterham PJ, Butterworth P, Nada-Raja S. The impact of suicidality on health-related quality of life: a latent growth curve analysis of community-based data. J Affect Disord. 2016;203:14-21. https:// doi.org/10.1016/j.jad.2016.05.067. 
12. Ponte C, Almeida V, Fernandes L. Suicidal ideation, depression and quality of life in the elderly: study in a gerontopsychiatric consultation. Span J Psychol. 2014;17:E14. https://doi.org/10.1017/sjp.2014.15.

13. Jaffe DH, Rive B, Denee TR. The burden of suicidal ideation across europe: a cross-sectional survey in five countries. Neuropsychiatr Dis Treat. 2019;15: 2257-71. https://doi.org/10.2147/NDT.S204265.

14. Beck A, Crain AL, Solberg LI, Unutzer J, Glasgow RE, Maciosek MV, et al. Severity of depression and magnitude of productivity loss. Ann Fam Med. 2011;9(4):305-11. https://doi.org/10.1370/afm.1260.

15. Siddiqui $\mathrm{S}$, Khalid J. Determining the caregivers' burden in caregivers of patients with mental illness. Pak J Med Sci. 2019;35(5):1329-33. https://doi. org/10.12669/pjms.35.5.720.

16. Wittenberg $E$, James LP, Prosser LA. Spillover effects on caregivers' and family members' utility: a systematic review of the literature. PharmacoEconomics. 2019;37(4):475-99. https:/doi.org/10.1007/s40273-019-00768-7.

17. Tabeleão VP, Tomasi E, Quevedo LD. Burden on relatives of people with psychic disorder: levels and associated factors. Revista de Psiquiatria Clínica. 2014;41(3):63-6. https://doi.org/10.1590/0101-60830000000012.

18. Girardi-Paskulin LM, Kottwitz-Bierhals CC, Oliveira dos Santos N, Baltar-Day C, de Oliveira-Machado D, Pinheiro de Morais E, et al. Depressive symptoms of the elderly people and caregiver's burden in home care. Investigación y Educación en Enfermería. 2017;35(2):210-20. https://doi.org/10.17533/udea. iee.v35n2a10.

19. Verbakel E, Tamlagsronning S, Winstone L, Fjaer EL, Eikemo TA. Informal care in Europe: findings from the European social survey (2014) special module on the social determinants of health. Eur J Pub Health. 2017; 27(suppl_1):90-5. https://doi.org/10.1093/eurpub/ckw229.

20. Verbakel E. How to understand informal caregiving patterns in Europe? The role of formal long-term care provisions and family care norms. Scand J Public Health. 2018;46(4):436-47. https://doi.org/10.1177/14034 94817726197

21. Petrini M, Cirulli F, D'Amore A, Masella R, Venerosi A, Carè A. Health issues and informal caregiving in Europe and Italy. Ann Is Super Sanita. 2019;55(1): 41-50. https://doi.org/10.4415/ANN_19_01_08.

22. Mcdonell MG, Short RA, Berry CM, Dyck DG. Burden in schizophrenia caregivers: impact of family psychoeducation and awareness of patient suicidality. Fam Process. 2003;42(1):91-103. https://doi.org/10.1111/j.1545-53 00.2003.00091.x.

23. Chessick CA, Perlick DA, Miklowitz DJ, Dickinson LM, Allen MH, Morris CD, et al. Suicidal ideation and depressive symptoms among bipolar patients as predictors of the health and well-being of caregivers. Bipolar Disord. 2009; 11(8):876-84. https://doi.org/10.1111/j.1399-5618.2009.00765.x.

24. Markey $E$. The impact of caregiving on the development of major depressive disorder and generalized anxiety disorder. J Eur Psychol Stud. 2015;6(1):17-24. https://doi.org/10.5334/jeps.cn.

25. Lerner D, Lavelle TA, Adler D, Chow W, Chang H, Godar SC, et al. A population-based survey of the workplace costs for caregivers of persons with treatment-resistant depression compared with other health conditions. J Occup Environ Med. 2020;62(9):746-56. https://doi.org/10.1097/JOM. 0000000000001957.

26. Balkaran BL, Jaffe DH, Umuhire D, Rive B, Milz RU, Nguyen JL. Impact on Quality of Life and Productivity Associated with Caregiving for Adults with Depression. 2019. ISPOR Europe Conference.

27. Roth DL, Fredman L, Haley WE. Informal caregiving and its impact on health: a reappraisal from population-based studies. Gerontologist. 2015; 55(2):309-19. https://doi.org/10.1093/geront/gnu177.

28. Kim Y, Schulz R. Family caregivers' strains. J Aging Health. 2008;20(5):483503. https://doi.org/10.1177/0898264308317533.

29. Rosen C, Marvin R, Reilly JL, DeLeon O, Harris MSH, Keedy SK, et al. Phenomenology of first-episode psychosis in schizophrenia, bipolar disorder, and unipolar depression. Clin Schizophr Relat Psychoses. 2012;6(3): 145-151A. https://doi.org/10.3371/CSRP.6.3.6.

30. Cuellar AK, Johnson SL, Winters R. Distinctions between bipolar and unipolar depression. Clin Psychol Rev. 2005;25(3):307-39. https://doi.org/10.1 016/j.cpr.2004.12.002.

31. Charlson ME, Pompei P, Ales KL, MacKenzie CR. A new method of classifying prognostic comorbidity in longitudinal studies: development and validation. J Chronic Dis. 1987;40(5):373-83. https://doi.org/10.1016/0021-9681(87)90171-8.

32. Ware J, Kosinski M, Turner-Bowker D, Gandek BMM. User's manual for the SF-12v2 health survey second edition. Lincoln: QualityMetric Incorporated; 2007.
33. Montazeri A, Vahdaninia M, Mousavi SJ, Asadi-Lari M, Omidvari S, Tavousi M. The 12-item medical outcomes study short form health survey version 2.0 (SF-12v2): a population-based validation study from Tehran, Iran. Health Qual Life Outcomes. 2011:9:12.

34. Frendl DM, Ware JE. Patient-reported functional health and well-being outcomes with drug therapy. Med Care. 2014;52(5):439-45. https://doi.org/1 0.1097/MLR.000000000000010311.

35. Brazier J, Roberts J, Deverill M. The estimation of a preference-based measure of health from the SF-36. J Health Econ. 2002;21(2):271-92. https:// doi.org/10.1016/S0167-6296(01)00130-8.

36. Leidl R, Reitmeir P. An experience-based value set for the EQ-5D-5L in Germany. Value Health. 2017;20(8):1150-6. https://doi.org/10.1016/j.jval.2017. 04.019.

37. Badia X, Roset M, Montserrat S, Herdman M, Segura A. The Spanish version of EuroQol: a description and its applications. European Quality of Life scale. Med Clin. 1999;112(S1):79-85.

38. Herdman M, Gudex C, Lloyd A, Janssen M, Kind P, Parkin D, et al. Development and preliminary testing of the new five-level version of EQ-5D (EQ-5D-5L). Qual Life Res. 2011;20(10):1727-36. https://doi.org/10.1007/s1113 6-011-9903-X.

39. Walters SJ, Brazier JE. Comparison of the minimally important difference for two health state utility measures: EQ-5D and SF-6D. Qual Life Res. 2005; 14(6):1523-32. https://doi.org/10.1007/s11136-004-7713-0.

40. Reilly MC, Zbrozek AS, Dukes EM. The validity and reproducibility of a work productivity and activity impairment instrument. PharmacoEconomics. 1993; 4(5):353-65. https://doi.org/10.2165/00019053-199304050-00006.

41. Pinquart $M$, Sörensen $S$. Correlates of physical health of informal caregivers: a meta-analysis. J Gerontol B Psychol Sci Soc Sci. 2007;62(2):P126-37. https://doi.org/10.1093/geronb/62.2.P126.

42. Rhee YS, Yun YH, Park S, Shin DO, Lee KM, Yoo HJ, et al. Depression in family caregivers of Cancer patients: the feeling of burden as a predictor of depression. J Clin Oncol. 2008;26(36):5890-5. https://doi.org/10.1200/JCO.2 007.15.3957.

43. Adelman RD, Tmanova LL, Delgado D, Dion S, Lachs MS. Caregiver Burden. JAMA. 2014;311(10):1052-60. https://doi.org/10.1001/jama.2014.304.

44. Minichil W, Getinet W, Derajew H, Seid S. Depression and associated factors among primary caregivers of children and adolescents with mental illness in Addis Ababa, Ethiopia. BMC Psychiatry. 2019;19(1):1-9. https://doi.org/1 0.1186/s12888-019-2228-y.

45. Duxbury L, Higgins C, Smart R. Elder care and the impact of caregiver strain on the health of employed caregivers. Work. 2011;40(1):29-40. https://doi. org/10.3233/WOR-2011-1204.

46. Richardson J, Khan MA, lezzi A, Maxwell A. Comparing and explaining differences in the magnitude, content, and sensitivity of utilities predicted by the EQ-5D, SF-6D, HUI 3, 15D, QWB, and AQoL-8D multiattribute utility instruments. Med Decis Mak. 2015;35(3):276-91. https://doi.org/10.1177/02 72989X14543107.

47. Hopps M, ladeluca L, McDonald M, Makinson GT. The burden of family caregiving in the United States: work productivity, health care resource utilization, and mental health among employed adults. J Multidiscip Healthc. 2017;10:437-44. https://doi.org/10.2147/JMDH.S135372.

\section{Publisher's Note}

Springer Nature remains neutral with regard to jurisdictional claims in published maps and institutional affiliations.

\section{Ready to submit your research? Choose BMC and benefit from:}

- fast, convenient online submission

- thorough peer review by experienced researchers in your field

- rapid publication on acceptance

- support for research data, including large and complex data types

- gold Open Access which fosters wider collaboration and increased citations

- maximum visibility for your research: over $100 \mathrm{M}$ website views per year

At BMC, research is always in progress.

Learn more biomedcentral.com/submission 